\title{
Experienced, but not naïve, birds use herbivore-induced plant volatiles to locate prey, learning one tree species at a time.
}

\author{
Katerina Sam ${ }^{1}$, Eliska Kovarova ${ }^{2}$, Inga Freiberga ${ }^{1}$, Henriette Uthe $^{3}$, Alexander Weinhold ${ }^{3}$, \\ and Rachakonda Sreekar ${ }^{1}$ \\ ${ }^{1}$ Biology Centre Czech Academy of Sciences \\ ${ }^{2}$ University of South Bohemia in Ceske Budejovice \\ ${ }^{3}$ Friedrich Schiller University Jena
}

August 28, 2020

\begin{abstract}
In tritrophic interactions, birds are able to detect herbivore-induced plant volatiles and use them as a signal of presence of arthropods on plant. It remains unclear whether this ability is innate or learned and how the birds react to novel odours. We studied whether and how naïve and trained great tits (Parus major) discriminate between herbivore-induced and noninduced saplings of potentially familiar and novel plant species. Birds trained to discriminate between saplings of either novel or familiar plant species preferred the induced saplings of the plants species they were trained to. Naïve birds did not show any preferences. Our results indicate that the attraction of great tits to herbivore-induced trees is not innate. Yet, the skill can be acquired through learning and novelty of the odour doesn't seem to be important. This implies that birds are learning whole bouquets of the herbivore-induced volatile compounds, rather than specific compounds individually.
\end{abstract}

\section{Introduction}

Plants attacked by herbivorous arthropods release volatiles (herbivore-induced plant volatiles, HIPVs) that might be used by natural enemies of the herbivores to locate prey or host (Dicke et al. 1990, Vet \& Dicke 1992, Takabayashi \& Dicke 1996, Dicke et al. 2009, Dicke 2015). The HIPVs that plants release in response to herbivory vary with the plant and insect species (De Moraes et al. 1998, Dicke et al. 1998, Mumm \& Dicke 2010, Hare 2011), and the herbivore density (Girling et al. 2011, Pisani Gareau et al. 2013, Cai et al. 2014). For many predators, it remains unknown whether the ability to find the prey with the aid of olfactory signals is innate or learned. Previous experience was shown to modulate olfactory responses in insects (Vet \& Dicke 1992, Steidle \& Van Loon 2003), rabbits (Semke et al. 1995) and fish (Nevitt \& Dittman 1998). In contrast, use of olfaction in searching for their hosts was shown to be an innate trait in parasitoids (Dicke \& van Loon 2000, Dicke 2015). It was not known until 2004 that also birds are attracted to trees infested by defoliator larvae, without the need to see larvae or physical damage they cause to foliage (Mäntylä et al. 2004, Mäntylä et al. 2008, Mäntylä et al. 2016, 2020). The mechanism of use of olfactory signals by birds searching for prey were not disentangled until recently (Amoet al. 2013a, Koski et al.2015, but see Koski et al. 2015). Rigid experimental work on bird's innate abilities to recognize odours, or to learn them, is missing.

Reportedly, some bird species need previous experience with volatile compounds before they are able to associate them with a particular food (Sneddon et al. 1998, Mennerat et al. 2005, Gwinner \& Berger 2008, Cunningham \& Nevitt 2011, Caspers et al. 2013). In contrast, use of olfaction in foraging was shown to be innate in some procellariform bird species (Bonadonnaet al. 2006, Amo et al.2013b). A rare experimental work, with naïve birds exposed to visual and olfactorial signals separately, implied that naïve birds did not show any preference for olfactory signal of herbivore-induced apple saplings compared to olfactory signal of 
uninfested control saplings (Amo et al. 2016). In contrast, when the naïve birds were allowed to gain some experience with foraging for caterpillars in trees, they exhibited a preference for olfactory signal of caterpillar infested trees (Amoet al. 2013a).

While the innate detection of HIPVs may be under strong selection pressure for specialized species (e.g. parasitoids), generalist predators may need to adapt their foraging behaviour in response to changes in the availability, distribution and abundance of prey species (e.g. Murakami 1998, 2002). Under these circumstances, natural selection may have favoured the ability to adaptively associate different scents with the food resource in order to maximise the foraging effort for different plant and insect species (Royama 1970), rather than having this ability innately (Amo et al. 2016).

To our knowledge, no previous study tested the response of birds to evolutionarily familiar and unfamiliar HIPVs. In our experiment, we aimed to investigate whether the great tits (Parus major) are able to learn various HIPVs, how quickly, and whether they are able to associate the evolutionarily unfamiliar and familiar plant volatile compounds with prey.

\section{Material and methods}

Experimental trees and their induction

In our experiment, we aimed to test responses of naïve chicks of great tits (Parus major ) to an evolutionarily familiar odour of herbivore-damaged Scotch elm, Ulmus glabra Huds. (Ulmaceae), and evolutionarily novel odour of herbivore-damaged Cattley guava Psidium cattleyanum Sabine (Myrtaceae). We used saplings (1.5-m-tall) of Cattley guava as a novel plant species, which did not have any evolutionary contact with our experimental bird species. Genus Psidium was distributed throughout tropical America and Caribbean region. However, they were adopted as a crop in subtropical and tropical Asia, tropical Africa and Oceania. SeveralPsidium cultivars are also commercially grown in southwestern Europe and Greece since the middle of the $20^{\text {th }}$ century. Scotch elm (1.5-m-tall) was used as a sapling which naturally occurs in the great tit range of distribution, and birds thus have evolutionary contact with them. Saplings were planted in 201 pots into a standard agricultural soil two months prior to the beginning of the experiment. Control $(\mathrm{N}=$ 10) and experimental (induced) saplings $(\mathrm{N}=10)$ were placed into two greenhouses just prior start of the experiment, so the control saplings can't receive chemical signals from induced saplings. All saplings were watered weekly.

To prepare the induced version of a sapling (i.e. those which will produce herbivore-induced volatile compounds), we slightly scratched 10 leaves by razor and applied saliva of Locusta migratoria on them. After 30 minutes, we removed the damaged leaves. In this way, plants started to produce herbivore induced volatile compounds, but the "herbivorous" damage was not visible to the birds. For training as well as experiments, new saplings were prepared this way every 4 hours, i.e. for every $9^{\text {th }}$ trial in experiment. In total, we used 30 individuals of each plant species.

We predicted that untrained, naïve birds, will not show any preferences for any saplings, with no respect whether the sapling provides olfactorial signal of insect infestation or not, and without respect whether the species is evolutionarily familiar or not. On the other hand, we predicted that birds trained to find food on saplings of experimental species will prefer that species also in pair-wise preference tests. Finally, we predicted that birds will more easily learn the volatile compounds of the tree species, which is evolutionarily familiar, and naturally occurs in their distributional range, than the volatile compounds of a completely novel, evolutionarily unfamiliar, volatile compounds.

\section{Birds and their training}

We used 30 naïve adult great tits as our model insectivorous bird species. All birds were collected from nest boxes when 10-13 days old; between 22nd and 24th of May 2018. All chicks from a given nest (4-6 chicks per nest), were kept together in one cage until fledging. Cages had dimensions $0.7 \times 0.4 \times 0.5 \mathrm{~m}$ with three perches. The birds were kept under natural winter daylight (8:15 to 17:00) augmented with fluorescent light tubes and automatically opened/closed window shades. After fledging, birds were moved to cages in groups 
of two to three birds, irrespective of their sex. Up to that period, chicks were individually hand fed every half-hour with hand rearing food for all bird chicks (Nutribird a21), a bread-like diet (made from Nutribird a21, commercial chicken food (Country's Best Show 1 crumble), eggs, wheat flower, sugar and sunflower margarine, mixed and baked for $\sim 40$ minutes at $\sim 180 \mathrm{degC}$ temperature) supplemented with mealworms. This was repeated for a period of $13.5 \mathrm{~h}(6: 45 \mathrm{am}-8: 15 \mathrm{pm})$ every day. Hand feeding was continued after fledging, but the intervals were prolonged to $1 \mathrm{~h}$ and later $4 \mathrm{~h}$, to stimulate birds to feed by themselves. At independence, about 35 days after hatching, birds were relocated to individual cages. From then on, the baked diet, mixed seeds, commercial dried insects (Nobby Orlux Insect Patee Premium) and water were provided ad libitum. Mealworms were offered only as supplementary food. During the whole period of captivity, chicks from different nests could hear and see each other, since they were raised in the same room.

None of the birds used in the experiment had previous direct experience with foliage or plant volatiles except that they could have been indirectly exposed to some plant cues associated with caterpillars and other herbivorous insects fed to them by their parents in the first 10-13 days after hatching. As Cattley guava naturally occurs in South America, its volatiles are evolutionary unfamiliar to the birds used in our experiment. Moreover, the bird chicks came from nest boxes placed in mixed oak-spruce forest, with no Scotch elm trees present in the surroundings. As HIPVs are plant-specific, we can consider that the birds used in our experiment are naive to HIPVs emitted by both sapling species used in the experiment. While Cattley guava represented a completely novel signal to the birds, Scotch elm represented a signal to which the birds could be evolutionarily adapted. Birds were randomly assigned into three training groups: (1) to associate food with the HIPVs of the Cattley guava, (2) to associate food with the HIPVs of the Scotch elm, and (3) not trained to associate food with any green foliage.

We performed all training, and experiments, in two Y-shaped aviaries built with mesh screens (Figure S1). Two $2 \mathrm{~m}$ tall dead Pedunculate oaks in a large pot were placed in the corners of the aviary and served as a perch. The birds whom we conditioned to find food in induced Cattley guava were offered one induced Cattley guava with 5 mealworms pinned to the leaves and one control cattle guava without any mealworms. The position of the induced and control cattle guava (left or right corner) in the aviary was selected randomly. Birds were allowed to habituate to the aviary and search for food, thus associate the volatile compounds of guava with the reward, for 1.5 hour every day. The birds were released to the aviary in pairs to make the learning (from each other) faster in first 3 trials. We conditioned birds to the volatile compounds of elm the same way. To condition the control birds to the cage, and initiate their interest in searching for food, we pinned 5 mealworms directly on one of the dead Pedunculate oaks. We conducted one training trial per bird daily. After each training trial, we checked how many meal worms were eaten. We considered the birds to be conditioned to the volatile compounds of the specific plant after they repeatedly ate at least 4 out of the 5 mealworms from the induced sapling.

It took 15 trials to condition all the birds to the induced saplings successfully. Some (40\%) birds did not pay too much attention to the plants during the first five trials but investigated mostly the aviary netting and surroundings. After first five training trials, we started to record some missing mealworms in most of the bird individuals, while some $(20 \%)$ bird individuals took at least 10 trials until they started eating mealworms. After $15^{\text {th }}$ trial, all birds successfully searched for meal worms on the induced saplings. This contrasted with previously described similar training, during which birds were able to find the larvae on sapling after fifth acclimatization (Amo et al. 2013a).

\section{Experimental design and procedure}

To examine whether great tits were able to learn the specific volatiles of the plant species, and associate it with the food, we performed a two-choice experiment in the same aviaries where the training was conducted. We offered all possible pairwise combinations of plant treatments, except both Control plants, to birds with all types of training. This comprised five plant combinations and three bird training treatments (Table 1). All birds participated in all five experiments, i.e. we conducted 145 trials in total.

All experimental trials were performed during 5 days (20 - 28 Aug 2018), between 09:00 and 17:00, under 
sunny and warm conditions to avoid variation in the emission of volatiles due to differences in ambient conditions such as temperature (Vallatet al. 2005). On each experimental day, a new pair of saplings was placed in the aviary prior to the first trial, and then replaced by a new pair of saplings after every four hours. In contrast to training trials, there were no mealworms pinned to any of the saplings during the experiment. Apart from that, the saplings were prepared the same way as for the training. We conducted two trials in two aviaries simultaneously. Prior to each experimental trial, the birds were starved in their housing cages for 90 minutes. This ensured that the birds were motivated to search for larvae on the saplings in the experimental aviary. After each training (or experimental trial), the bird was captured with a net and returned to its cage. We recorded the behaviour of birds in the aviary during the 20 min long trials using a video camera (Panasonic Full HD V180EP-K). One observer, unaware of the treatment, analysed the video tapes, recorded the time spent on each of the saplings (i.e., on the trunk inspecting the foliage form there, or in the foliage) and the time spent in the proximity of the sapling (i.e., within $50 \mathrm{~cm}$ from the sapling, on the netting of the cage, or on the pot, but only when the bird paid visible attention to the sapling). A new experimental trial started every 30 minutes, while 5 minutes were allowed for the catching and replacement of birds, and the first 3-5 minutes of the video recording were discarded to account for the acclimatization of the bird to the cage.

\section{Chemical analyses}

We performed gas chromatography to quantify the sampled VOCs. We sampled the volatile compounds of the two plant species by passive trapping with polydimethylsiloxane (PDMS) tube cuttings following a modified protocol of that used by (Kallenbach et al. 2015) and (Klimm et al.2020). Using the PDMS tubes, we sampled volatile compounds from ca. half of the saplings. First, we attached the tubes by copper wire to the experimental sapling. We then tightly enclosed as many leaves as possible and the PDMS tube in polyamide oven bags. We sampled VOCs from the headspace for 24 hours. We removed the tubes, placed them to sterile glassy vials and brought them to lab for further analyses. The PDMS cuttings were analysed by a thermal desorption-gas chromatograph-mass spectrometer (TD-GC-MS) consisting of a thermodesorption unit (MARKES, Unity 2, Llantrisant, United Kingdom) equipped with an autosampler (MARKES, Ultra 50/50). PDMS cuttings were transferred to empty stainless steel tubes (MARKES) and desorbed with helium as carrier gas and a flow path temperature of $160 \mathrm{deg} C$ using the following conditions: dry purge 5 min at $20 \mathrm{ml} / \mathrm{min}$, pre purge $1 \mathrm{~min}$ at $10 \mathrm{ml} / \mathrm{min}$, desorption $8 \mathrm{~min}$ at 200degC with $60 \mathrm{ml} / \mathrm{min}$, trap temperature 0degC, pre trap fire purge $1 \mathrm{~min}$ at $60 \mathrm{ml} / \mathrm{min}$, split flow $20 \mathrm{ml} / \mathrm{min}$, trap heated to $230 \mathrm{degC}$ and hold for 4 min. The VOCs were separated on a gas chromatograph (Bruker, GC-456, Bremen, Germany) connected to a triple-quad mass spectrometer (Bruker, SCION) equipped with DB-WAX column: (30m x 0.25mm inner diameter x 0.25um film thickness, Restek). The temperature program was the following: 60degC (hold 1 $\mathrm{min}$ ), $30 \mathrm{deg} \mathrm{C} / \mathrm{min}$ to $150 \mathrm{deg} \mathrm{C}, 10 \mathrm{deg} \mathrm{C} / \mathrm{min}$ to $200 \mathrm{deg} \mathrm{C}$ and $30 \mathrm{deg} \mathrm{C} / \mathrm{min}$ to $230 \mathrm{degC}$ (hold $1 \mathrm{~min}$ ). Helium was used as carrier gas at a constant flow rate of $1 \mathrm{ml} / \mathrm{mi}$. MS conditions were set at a 40degC manifold, 240degC transfer line and $220 \mathrm{degC}$ for the ion source. The scan-range was $33-500 \mathrm{~m} / \mathrm{z}$ for a full scan and scan-time was $250 \mathrm{~ms}$. We selected the most prominent peaks in the chromatograms (signal to noise ratio $>$ 10). Peaks that were also present in air blanks were regarded as systemic contamination and were excluded from further analysis. VOCs were tentatively identified by comparison to the NIST database and comparison to retention indices from the literature. The peak areas of these compounds were calculated using the Bruker Workstation software (v8.0.1).

\section{Data analysis}

We used the proportion of time spent on each of the saplings for the analysis. We used the glmmTMB package (Brooks et al. 2017) within R 3.6.1 (R Core Team 2019) to build a generalised linear mixed model with a beta error structure and a logit link. Models that follow beta distribution only allow proportion values between 0 and 1 . Therefore, 0 and 1 values in our study were converted into 0.0001 and 0.9999 , respectively. We used the mixed model to determine the effect of experiment (sapling combination), bird training and their interaction on the proportion of time spent by an individual bird in proximity of each sapling. We used Anova function from 'car' package to calculate P-values for each variable using Wald chisquare test 
(Fox \& Weisberg 2018). We then made pairwise comparisons between the five experiments within each of the training types using the emmeans functions in 'emmeans' package that adjusts $\mathrm{P}$-values $\left(\mathrm{P}_{\text {adj }}\right)$ following the Tukey method (Lenth 2007).

The centroided GC-MS data in NetCDF format were further processed using XCMS online (version 2.7.2) The peaks in each sample were detected with the cent Wave algorithm (peak width 2-20 s; signal to noise threshold 10). Peak grouping across samples was restricted to peaks present in at least $50 \%$ of the samples in at least one treatment group $(\operatorname{minfrac}=0.5)$. Retention time correction was accomplished with the symmetric method and nonlinear loess-smoothing and iterated three times with decreasing bandwidth parameter for the grouping from 10 to $0.2 \mathrm{~s}$. The extracted ion species were grouped according to their parent molecule into pseudospectra with the Bioconductor package camera (Kuhlet al. 2012). This resulted in a final feature table containing mass-to-charge ratio $(\mathrm{m} / \mathrm{z})$, retention time, peak area and the pseudospectra group for each detected ion species. Groups containing only a single ion species were considered to be artefacts and removed from the final feature table. The feature table was uploaded to MetaboAnalyst for further statistical analyses. We performed quantile normalization and Log transformation. Pareto Scaling was chosen for Principal Component Analysis. The annotation of the most significant features was done by spectral library search (NIST) and MS spectra and Kovats Index comparison with standard compounds.

\section{Results}

The proportion of time spent by individual birds on a sapling was dependent of the combination of saplings, bird training, and significant interaction of both factors $\left(\mathrm{X}^{2}=31.62, \mathrm{P}=0.001\right)$. This result suggests that the difference between experiments is dependent of the type of training given to the individual bird.

Naive birds (control) spent around $50 \%$ of their time on each of the two saplings in four out of the five experiments (Fig. 1; Table S1). Elm trained birds spent significantly longer time on induced elm saplings than noninduced elm saplings (Figure 1). The time spent on each sapling varied significantly across experiments (Table 2). In experiments where herbivore induced elm saplings were presented with noninduced elm control (Exp 1) or noninduced guava (Exp 3), birds spent respectively $82 \%$ (69\% to $91 \%$ ) and $75 \%$ (58\% to $87 \%$ ) of their time on the induced saplings. In experiment 2, 4, and 5 birds spent equal amount of time on each treatment (Figure 1). When induced elm saplings were presented with induced guava saplings in experiment 2, birds only spent c. $56 \%$ ( $25 \%$ to $64 \%$ ) on induced elm. Experiments 4 and 5 did not contain induced elm samplings, but contained induced guava sapling, but the birds did not show any specific preference (Figure 1, Table S2).

Guava trained birds spent significantly higher amount of time on herbivore induced saplings than noninduced saplings (Figure 1). The time spent on each sapling varied significantly across experiments (Table S3). In experiments 4 and 5, where herbivore induced saplings were presented with non-induced saplings, birds spent c. $82 \%$ ( $67 \%$ to $91 \%)$ and $76 \%$ (58\% to $88 \%$ ) of their time on those saplings. In experiment 2, where herbivore induced guava saplings were presented with herbivore induced elm sapling, birds spent c. $71 \%$ ( $52 \%$ to $85 \%$ ) of their time on induced guava saplings. In experiments 1 and 3 where herbivore induced elm saplings were presented, birds did not show any specific preference (Figure 1).

\section{Induced volatiles of experimental plants}

We detected significantly more chemical compounds in induced than in noninduced guavas $(\mathrm{P}=0.009)$. Induced guavas had higher abundances of $\beta$-Ocimene, Heptadiene, Cyclohexane. Other significant compounds were $\alpha$-Pinene, Copaene, Caryophyllene, and Tetraline. In elm samples, $\beta$-Ocimene, $\alpha$-Farensene and Tetraline were the most significant compounds. Despite the induced elm produced more compounds that noninduced elm, the difference was not statistically significant (Figure S3). However, the induced elm had significantly higher abundances of 1-Butanol, 3-methyl-, acetate and 2-Butanone,4-(2,6,6-trimethyl-1cyclehexen-1-yl).

\section{Discussion}

Our results show that attraction of great tits to herbivore-induced defence cues is not innate. Naïve birds 
with no experience with green leaves were not attracted to induced, thus potentially insect rich, saplings. This confirms the previous findings of Amo et al.(2016). In their experiment, naïve birds neither preferred the caterpillar-infested sapling for the first visit, nor visited that sapling more frequently that the uninfested sapling (control). In contrast, in another study, when the great tits gained some experience with foraging for caterpillars, they exhibited a preference for caterpillar infested saplings, and visited them more often than the uninfested saplings (Amoet al. 2013a). In line with these results, we were able to teach the birds the association between the herbivore-induced volatile compounds of saplings and a food reward.

In contrast to our expectation, the great tits were able to associate the volatile compounds of tropical guava with food similarly well (if not better) as of the volatile compounds of elm, despite the fact that they did not share any evolutionary history with this plant species. After the successful teaching period, each group of trained bird preferred the induced version of the sapling of the plant species they were trained to, over any other version of the saplings offered to them. The birds did not seem to be able to generalize the learned bouquets of volatile compounds to another plant species. This might imply that the birds are likely to learn the whole bouquets of the volatile compounds and associate them with food, rather than learning individual volatile compounds. Alternative explanation might be that the birds are capable of some generalization for more closely related plant species producing more similar plant volatile compounds.

In our experimental plants, we detected significantly more chemical compounds in induced than in noninduced guavas. The volume of produced compounds was also higher in induced than in noninduced elms, but the difference was not significant. Compounds found in significantly higher concentration in induced plants were $\beta$-Ocimene, Heptadiene, Cyclohexane, $\alpha$-Pinene, Copaene, Caryophyllene, Tetraline, $\alpha$-Farensene and Tetraline. Many of these compounds were previously suspected to correlate with attractivity of the herbivoredamaged plants with bird's attractivity to them (Mrazova et al. 2019). Specifically, $\beta$-Ocimene and $\alpha$-Pinene were discussed as compounds specifically responsible for the attractivity of birds to herbivore-damaged plants (Mrazova et al.2019). Our experiment showed that birds exposed to two plants with very different bouquets can distinguish them better than birds exposed to more similar bouquets. In our experiment, we selected two plant species which are very different. One tropical plant with strong odour and one temperate with rather weak odour. Our birds were not able to generalize between their odours. The questions remain whether the birds would be capable of generalization between several temperate plant species which might have more similar odours.

In contrast to previous study (Amo et al. 2016), our birds took rather long to successfully search for the mealworms offered to them on induced saplings. The previous study indicated a fast ability of birds to use HIPVs as a foraging cue, as they learned to associate the presence of caterpillars with the HIPVs of infested trees in $5 \mathrm{~h}$ (Amo et al.2016). Similarly, in our previous study, naïve birds were able to locate more than $80 \%$ of caterpillars after $5 \mathrm{~h}$ of habituation in aviary with noninduced trees (Mrazova et al. unpublished). In the current study, the average bird needed at least 20 hours to be able to associate the food rich sapling with the volatile compounds. The difference between current and previous training was in the type of the sapling offered in training phase (two infested saplings in Amo et al. 2016 or two uninfested saplings in Mrazova et al. unpublished vs. one infested and one uninfested sapling in current study) and the training considered to be successful (i.e. eating from any sapling vs. eating from the induced sapling only).

A prenatal chemosensory learning was demonstrated in birds (Sneddon et al. 1998) previously but it a very different experiment with domestic chickens. With no exposure to strawberry before hatching, strawberry was highly aversive to chicks after hatching. However, following exposure to strawberry before hatching, chicks expressed a greater preference for (or weaker aversion to) the strawberry stimulus (Sneddon et al. 1998). Despite no association of smell and food was tested in this study, it proved that chicks can learn and prefer a smell. In a similar study, nest recognitions via olfactory imprinting was learned in few hours after hatching, and olfactory stimuli is then a sufficient mechanism for nest recognition (Caspers et al. 2013).

For birds, as generalist predators, prey availability changes during the year due to differences in phenology of the plant and insect species. Therefore, adaptive plasticity may be an advantage for foraging of the birds in response to changes in distribution and abundance of prey species (e.g. in Murakami 1998). In the 
current study, we showed the existence of such plastic association of different odours with food resources may maximize success of foraging in birds. We observed that birds are able to learn even novel odours which they did not have chance to meet during their evolutionary history. Thus, they are capable of some generalization with respect to volatile compounds. However, it is important to note that our study was conducted on a single bird species but the adaptive value of learning is expected to vary among bird species depending on their diet breadth at both the herbivore and plant levels (Vet et al. 1995, Mrazova et al. 2019). The use of olfaction in foraging can be innate in different bird species (Bonadonna et al. 2006, Amo et al. 2013b).

In our study, we also used very phylogenetically distant tree species, which differed significantly in the diversity of volatile compounds. However, it is likely that some generalization may work across more similar and phylogenetically related tree species. While birds might be able to learn several plant species occurring in their home ranges in temperate regions, the tropical birds might be facing different challenges. Tropical insectivorous understory birds have usually home ranges up to 30 ha large. A hectare of tropical forest typically contains more than 250 tree species. It would be generally impossible for a bird to learn all species in a lifetime, so either individual birds respond to only subset of local plants, or birds learn groups of plants which are chemically and therefore also phylogenetically related). It remains unresolved how the learning of volatile compounds works in species rich tropical areas, and how is the ability to learn volatile compounds combined with ability to learn the visual signals.

\section{Acknowledgments}

KS acknowledges Grant Agency of Czech Republic project 18-23794Y and European Research Council project BABE 805189. HU and AW gratefully acknowledge the German Research Foundation for funding the German Centre for Integrative Biodiversity Research (iDiv) Halle-Jena-Leipzig (DFG- FZT 118, 202548816).

\section{References}

Amo, L., Dicke, M., \& Visser, M.E. (2016). Are naïve birds attracted to herbivore-induced plant defences? Behav . 153, 353-366.

Amo, L., Jansen, J.J., Dam N.M., Dicke, M., \& Visser, M.E. (2013a). Birds exploit herbivore-induced plant volatiles to locate herbivorous prey. Ecol. Lett. 16, 1348-1355.

Amo, L., Rodriguez-Girones, M.A., \& Barbosa, A. (2013b). Olfactory detection of dimethyl sulphide in a krill-eating Antarctic penguin.Mar. Ecol. Prog. Series 474, 277-285.

Brooks, M.E., Kristensen, K., van Benthem, K.J., Magnusson, A., Berg, C.W., Nielsen, A. et al.(2017). glmmTMB balances speed and flexibility among packages for zero-inflated generalized linear mixed modeling. The $R$ journal , 9, 378-400.

Bonadonna, F., Caro, S., Jouventin, P. \& Nevitt, G. (2006). Evidence that blue petrel, Halobaena caerulea , fledglings can detect and orient to dimethyl sulfide. J. Exper. Biol. , 209, 2165-2169.

Cai, X.-M., Sun, X.-L., Dong, W.-X., Wang, G.-C. \& Chen, Z.-M. (2014). Herbivore species, infestation time, and herbivore density affect induced volatiles in tea plants. Chemoecology , 24, 1-14.

Caspers, B.A., Hoffman, J.I., Kohlmeier, P., Kruger, O. \& Krause, E.T. (2013). Olfactory imprinting as a mechanism for nest odour recognition in zebra finches. Anim. Behav. , 86, 85-90.

Cunningham, G.B. \& Nevitt, G.A. (2011). Evidence for olfactory learning in procellariiform seabird chicks. J. Avian Biol. , 42, 85-88.

Cunningham, G.B. \& Nevitt, G.A. (2011). Evidence for olfactory learning in procellariiform seabird chicks. J. Avian Biol. , 42, 85-88.

De Moraes, C.M., Lewis, W.J., Pare, P.W., Alborn, H.T. \& Tumlinson, J.H. (1998). Herbivore-infested plants selectively attract parasitoids. Nature, 393, 570-573. 
Dicke, M. (2015). Herbivore-induced plant volatiles as a rich source of information for arthropod predators: fundamental and applied aspects. J. Indian Instit. Sci. , 95, 35-42.

Dicke, M., Sabelis, M.W., Takabayashi, J., Bruin, J. \& Posthumus, M.A. (1990). Plant strategies of manipulating predator-prey interactions through allelochemicals: prospects for application in pest control.J. Chem. Ecol. , 16, 3091-3118.

Dicke, M., Takabayashi, J., Posthumus, M.A., Schutte, C. \& Krips, O.E. (1998). Plant-Phytoseiid interactions mediated by herbivore-induced plant volatiles: variation in production of cues and in responses of predatory mites. Exper. Appl. Acarology , 22, 311-333.

Dicke, M., van Loon, J.J. \& Soler, R. (2009). Chemical complexity of volatiles from plants induced by multiple attack. Nat. Chem. Biol. , 5, 317-324.

Dicke, M. \& van Loon, J.J.A. (2000). Multitrophic effects of herbivore-induced plant volatiles in an evolutionary context. Entomol. Exper. Appl. , 97, 237-249.

Fox, J. \& Weisberg, S. (2018).An R companion to applied regression . Sage publications.

Girling, R.D., Stewart-Jones, A., Dherbecourt, J., Staley, J.T., Wright, D.J. \& Poppy, G.M. (2011). Parasitoids select plants more heavily infested with their caterpillar hosts: a new approach to aid interpretation of plant headspace volatiles. P. Roy. Soc.B-Biol. Sci. , rspb20102725.

Gwinner, H. \& Berger, S. (2008). Starling males select green nest material by olfaction using experienceindependent and experience-dependent cues. Anim. Behav. , 75, 971-976.

Hare, J.D. (2011). Ecological role of volatiles produced by plants in response to damage by herbivorous insects. Ann. Rev. Entomol. , 56, 161-180.

Hoballah, M.E. \& Turlings, T.C. (2005). The role of fresh versus old leaf damage in the attraction of parasitic wasps to herbivore-induced maize volatiles. J. Chem. Ecol. , 31, 2003-2018.

Kallenbach, M., Veit, D., Eilers, E.J. \& Schuman, M.C. (2015). Application of silicone tubing for robust, simple, high-throughput, and time-resolved analysis of plant volatiles in field experiments. Bio-protocol, 5 .

Klimm, F.S., Weinhold, A. \& Volf, M. (2020). Volatile production differs between oak leaves infested by leaf-miner Phyllonorycter harrisella (Lepidoptera: Gracillariidae) and galler Neuroterus quercusbaccarum (Hymenoptera: Cynipidae). EJE , 117, 101-109.

Koski, T.M., Laaksonen, T., Mantyla, E., Ruuskanen, S., Li, T., Giron-Calva, P.S. et al. (2015). Do Insectivorous Birds use Volatile Organic Compounds from Plants as Olfactory Foraging Cues? Three Experimental Tests. Ethology , 121, 1131-1144.

Kuhl, C., Tautenhahn, R., Bottcher, C., Larson, T.R. \& Neumann, S. (2012). CAMERA: an integrated strategy for compound spectra extraction and annotation of liquid chromatography/mass spectrometry data sets. Anal. Chem. , 84, 283-289.

Lenth, R.V. (2007). Statistical power calculations. J. Anim. Sci. , 85, E24-E29.

Mantyla, E., Alessio, G.A., Blande, J.D., Heijari, J., Holopainen, J.K., Laaksonen, T. et al. (2008). From Plants to Birds: Higher Avian Predation Rates in Trees Responding to Insect Herbivory. PLoS ONE , 3, e2832.

Mantyla, E., Kleier, S., Kipper, S. \& Hilker, M. (2016). The attraction of insectivorous tit species to herbivore-damaged Scots pines. J. Ornithol. , 1-13.

Mantyla, E., Klemola, T. \& Haukioja, E. (2004). Attraction of willow warblers to sawfly-damaged mountain birches: novel function of inducible plant defences? Ecol. Lett. , 7, 915-918. 
Mantyla, E., Kipper, S. \& Hilker, M. (2020). Insectivorous birds can see and smell systemically herbivoreinduced pines. Ecol. Evol.(in early view - https://doi.org/10.1002/ece3.6622)

Mennerat, A., Bonadonna, F., Perret, P. \& Lambrechts, M. (2005). Olfactory conditioning experiments in a food-searching passerine bird in semi-natural conditions. Behav. Proc. , 70, 264-270.

Mrazova, A., Sam, K. \& Amo, L. (2019). What do we know about birds' use of plant volatile cues in tritrophic interactions? Curr. Opinin. Insect Sci. , 32, 131-136.

Mumm, R. \& Dicke, M. (2010). Variation in natural plant products and the attraction of bodyguards involved in indirect plant defense.Canad. J. Zool. , 88, 628-667.

Murakami, M. (1998). Foraging habitat shift in the narcissus flycatcher, Ficedulanarcissina, due to the response of herbivorous insects to the strengthening defenses of canopy trees. Ecol. Res. , 13, 73-82.

Murakami, M. (2002). Foraging mode shifts of four insectivorous bird species under temporally varying resource distribution in a Japanese deciduous forest. Ornithol. Sci. , 1, 63-69.

Nevitt, G. \& Dittman, A. (1998). A new model for olfactory imprinting in salmon. Integrative Biology: Issues, News, and Reviews: Published in Association with The Society for Integrative and Comparative Biology , 1, 215-223.

Pisani Gareau, T.L., Letourneau, D.K. \& Shennan, C. (2013). Relative densities of natural enemy and pest insects within California hedgerows. Environ. Entomol. , 42, 688-702.

Royama, T. (1970). Factors governing the hunting behaviour and selection of food by the great tit (Parus major L.). J. Anim. Ecol. , 619-668.

Scascighini, N., Mattiacci, L., D’Alessandro, M., Hern, A., Rott, A.S. \& Dorn, S. (2005). New insights in analysing parasitoid attracting synomones: early volatile emission and use of stir bar sorptive extraction. Chemoecology, 15, 97-104.

Semke, E., Distel, H. \& Hudson, R. (1995). Specific enhancement of olfactory receptor sensitivity associated with foetal learning of food odors in the rabbit.Naturwissenschaften , 82, 148-149.

Sneddon, H., Hadden, R. \& Hepper, P. (1998). Chemosensory learning in the chicken embryo. Phys. Behav. , 64, 133-139.

Steidle, J.L. \& Van Loon, J.J. (2003). Dietary specialization and infochemical use in carnivorous arthropods: testing a concept. Entomol. Exper. Appl. , 108, 133-148.

Takabayashi, J. \& Dicke, M. (1996). Plant-carnivore mutualism through herbivore-induced carnivore attractants. Trends Plant Sci. , 109-113.

Takabayashi, J., Takahashi, S., Dicke, M. \& Posthumus, M. (1995). Developmental stage of herbivorePseudaletia separata affects production of herbivore-induced synomone by corn plants. J. Chem. Ecol. 21, 273-287.

Vallat, A., Gu, H. \& Dorn, S. (2005). How rainfall, relative humidity and temperature influence volatile emissions from apple trees in situ. Phytochemistry , 66, 1540-1550.

Vet, L.E., Lewis, W.J. \& Carde, R.T. (1995). Parasitoid foraging and learning. In: Chemical ecology of insects 2. Springer, pp. 65-101.

Vet, L.E.M. \& Dicke, M. (1992). Ecology of infochemical use by natural enemies in a tritrophic context. Ann. Rev. Entomol. , 37, 141-172.

Table 1. Overview of the experimental design using three groups of birds and five combinations of saplings for 145 trials (20 mins each) that used 29 individual birds. 


\begin{tabular}{llllll} 
Trained to: & Experiment 1 & Experiment 2 & Experiment 3 & Experiment 4 & Experiment 5 \\
& Induced elm & Induced guava & Induced elm & Induced guava & Induced guava \\
& Control elm & Induced elm & Control guava & Control elm & Control guava \\
Elm & 10 & 10 & 10 & 10 & 10 \\
Guava & 9 & 9 & 9 & 9 & 9 \\
Naïve & 10 & 10 & 10 & 10 & 10 \\
\hline
\end{tabular}

Figure 1. The preference of birds towards individual treatments, estimated by the generalised linear mixed model. The proportion of time spent by birds with different training on each sapling across all experiments. Naïve (control) birds did not show a significant preference of either sapling, while elm and guava trained birds preferred herbivore induced saplings of the species on which they were trained, except for Exp 2 for elm trained birds.
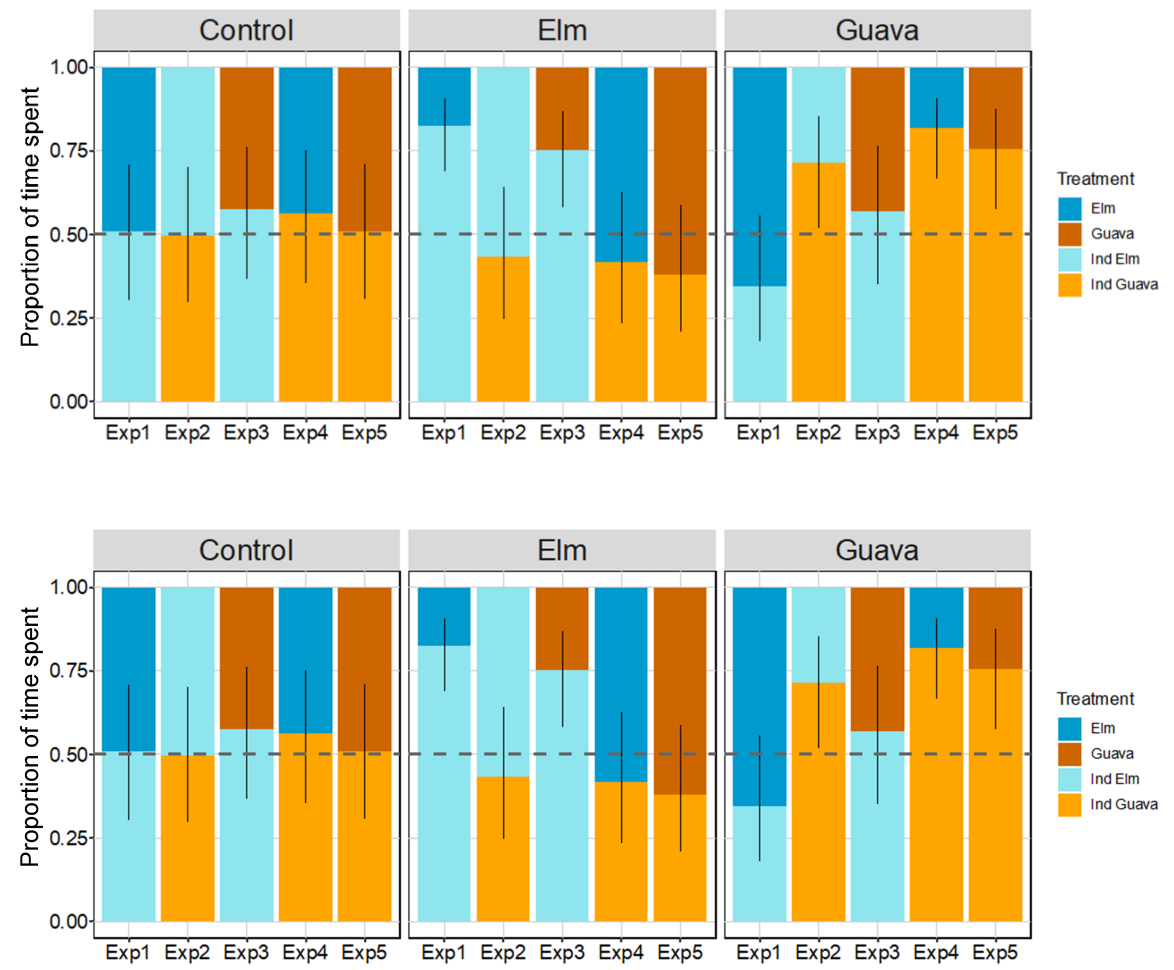